\title{
Foreword to the first edition by S. Venkataraman
}

Every now and then one comes upon a genuinely new idea. Professor Saras Sarasvathy's idea of effectuation is one such. Effectuation is a refreshingly new look at the old phenomenon of entrepreneurship. Indeed, it is a wholly new way of looking at the world around us. After reading this book, you will never look at the world of entrepreneurship the same way again. Sarasvathy's work is based on a beautiful narrative, profound theory, a deep and visceral understanding of the entrepreneurship phenomenon, and everyday facts and events; and it is eminently practical - virtues that are bound to make it a classic in a short period.

Core to effectuation is the idea that rather than discover and exploit opportunities that pre-exist in the world, the effectual entrepreneur is one who 'fabricates' opportunities from the mundane realities of her life and value systems. In the evocative phrase of Sarasvathy, entrepreneurs fabricate opportunities by starting with who they are, what they know, and whom they know - in short, all someone needs to create an entrepreneurial legacy in this world is to begin with their intellectual capital, human capital and social capital. At once liberating and practical, this simple idea forms the foundation for a beautiful theory of the 'made' world rather than the 'found' world that populates much of the textbooks and journal pages of the entrepreneurship literature. Significantly, she does not sell entrepreneurship short by interpreting it as a prosaic activity of starting a new business venture for a commercial activity. Rather, she breathtakingly announces that since all markets are ultimately markets in human hope, and since all economic value ultimately derives from human beings, any activity that involves the design and creation of products, services, institutions and other human artifacts that addresses this human hope and value falls within the sphere of effectual entrepreneurship.

Central to Sarasvathy's effectuation are two building blocks: the science of the artificial (which, in the context of entrepreneurship, she re-labels science of the artefactual) and pragmatism. As she suggests, the study of entrepreneurship as an artefactual science allows us to ask design-oriented questions rather than 'why' questions or 'explain (immutable) dependence relationships' that are so characteristic of the natural sciences and even many social sciences that aim to mimic natural sciences. Thus, our focus shifts from asking, 'why 
do some people become entrepreneurs?' to 'what are the barriers to entrepreneurship?' Similarly, the question that most MBA entrepreneurship programs focus on, namely, 'How do I become a successful entrepreneur?' is replaced in the effectual world by 'Given who I am, what I know, and whom I know, what kind of entrepreneur could I become; what kind of entrepreneurial activities could I pursue; and what kind of enterprises could I create?' Designing and principles of design and designing then become integral to entrepreneurship.

The second building block in effectuation is the pragmatist method. As Sarasvathy notes, the pragmatist approach allows one to develop design principles for fabricating human artifacts through the entrepreneurial process. What is a firm (or for that matter a market) if not a human artifact? By emphasizing the practical and instrumental courses of action in any situation, rather than seeking a general theory, or some notion of context free 'true' statements, Sarasvathy provides effectuation with a useful and powerful methodology to talk about design and designing the artefactual. As she most eloquently states, "whether the all-important idea is "God" or "gravity" or "market" the pragmatist is not chasing the holy grail or even $a$ holy grail. Instead, she seeks to make grails, mend them, remake them into urns or other useful artifacts.'

This book is intellectually breath-taking - for its audacity and bold theorizing, for the literary quality of its narrative, for the poignancy of its examples and cases, and for the implications for everyday life - from the prosaic to the profound. Indeed, the chapter on 'Markets in Human Hope' (Chapter 10) alone is worth the price of the book - for all of the above qualities listed. After reading the book one will admit 'effectuation matters'. Surprisingly, it will be for reasons that one had not thought of before. To very slightly paraphrase Sarasvathy, it matters because how we think about the world influences how we frame problems, what alternatives we perceive and generate; which constraints we accept, reject, and/or manipulate and how; and why we heed certain criteria rather than others in fabricating and implementing new solutions. Thanks to Sarasvathy's new framing, I see a new dawn for the field of entrepreneurship and beyond.

It is a privilege to write the foreword to this last book under my editorship of this series on New Horizons in Entrepreneurship. I cannot think of a better way to sign off.

Sankaran Venkataraman

Series Editor 